\title{
BOÉCIO DE DÁCIA SOBRE O BEM SUPREMO*
}

Tradução de

Luis A. De Boni**

Para toda a espécie de ente existe um supremo bem possível. Como o homem também é ente de uma certa espécie, deve haver também um certo bem supremo que lhe seja possivel. Não me refiro ao bem supremo em sentido absoluto, mas o supremo bem para o homem, visto que os bens possiveis ao homem têm um fim e não procedem ao infinito.

Investiguemos pela razão qual seja este supremo que é possível ao homem. Deve ser ele um bem que se atribui à sua virtude superior. Não se trata, pois, de algo referente à alma vegetativa - que é própria das plantas - nem de algo referente a alma sensitiva - que é própria dos animais, e por isso os deleites sensiveis pertencem aos animais. A virtude superior do homem é a razão e a inteligência; e constitui a direção da vida humana tanto na teoria como na prática. Portanto, o bem supremo, que é possivel ao homem, refere-se à sua inteligência.

Por isso, devem doer-se os homens que se atêm apenas aos deleites sensiveis, porque relegam os bens intelectuais e assim jamais atingem seu bem supremo. Entregam-se tanto aos sentidos, a ponto de não procurarem o que é bem próprio do intelecto. Contra eles clama o Filósofo, quando diz: "Ai de vós, homens, que sois contados entre o número dos brutos, pois não cuidais daquilo que em vós é divino" [texto não encontrado]. O que ele chama de divino no homem é o intelecto. De fato, se algo de divino existe no homem, é digno que seja o intelecto. Assim, pois, como é divino aquilo que é ótimo no conjunto de todos os entes, assim também chamamos de divino àquilo que é o supremo no homem.

Ora, no intelecto humano há uma potência especulativa e uma prática. Isto se manifesta pelo fato de que o homem por vezes é especulativo, a respeito daquelas coisas sobre as quais não exerce sua atividade, como no caso das coisas eternas; e por vezes é também ativo, segundo a determinação do intelecto, ao escolher uma coisa intermediária em todas as ações humanas. Assim sabemos que há genericamente no homem estas duas potências intelectuais.

\footnotetext{
* Opera VI-I. Green-Pedersen (ed.) Hauniae: GECGAD, 1976, p. 367-377.

** PUCRS
} 
O bem supremo possivel ao homem, segundo a potência especulativa do intelecto, é o conhecimento da verdade e o deleite nela. O conhecimento da verdade causa deleite. Aquilo que é conhecido deleita a quem conhece e, por isso, quanto mais admirável e mais nobre for o que é conhecido, e quanto maior força tiver o intelecto para compreender perfeitamente, tanto maior será o deleite intelectual. $\mathrm{E}$ quem experimentou tal deleite despreza todos os deleites menores, como o sensível, que em verdade é menor e mais vil. E o homem que elege este deleite é, devido a ele, mais vil que aquele que elege o deleite intelectual.

Pelo fato que aquilo que é entendido deleita a quem entende, o Filósofo conclui (IX Met. C. 7, 1072b 24) que o intelecto primeiro possui uma vida cheia de voluptuosidade. Ora, o primeiro intelecto possui maior capacidade de conhecer, e aquilo que ele conhece é nobilíssimo, pois é a sua própria essência - e o que pode o intelecto divino conhecer de mais nobre que a essência divina? Por isso, ele possui uma vida cheia de voluptuosidade. Portanto, nenhum bem maior pode provir ao homem através do intelecto especulativo que o conhecimento da totalidade dos entes que provêm do primeiro princípio e, através disso, na medida do possível, o conhecimento do primeiro princípio e o deleite nele. Segue-se, pois, como se conclui acima, que o supremo bem possivel para o homem, segundo o intelecto especulativo, é o conhecimento da verdade nas coisas singulares e o deleite nela.

Do mesmo modo, o supremo bem possível ao homem, segundo o intelecto prático, é a operação do bem e o deleite nele. De fato, que bem maior poderia acontecer ao homem, segundo o intelecto prático, do que operar livremente o bem em todas as ações humanas e deleitar-se nele? Só é justo aquele que se deleita nas obras da justiça - e do mesmo modo deve-se entender a respeito das obras das demais virtudes morais.

Do que foi dito pode-se concluir claramente que o supremo bem possivel ao homem consiste no conhecimento da verdade, na prática do bem e no deleite em amibos.

E como o supremo bem possivel ao homem constitui a sua felicidade, seguese que 0 conhecimento da verdade, a prática do bem e o deleite em ambos são a felicidade humana. Em vista disso é que a arte militar é organizada pelo legislador: para que, expulsos os inimigos, os cidadãos possam entregar-se às virtudes intelectuais, contemplando a verdade, e às virtudes morais, praticando o bem, e assim vivam uma vida feliz, que consiste nestas duas coisas.

Este, pois, é o maior bem que o homem pode receber de Deus, e que Deus pode dar ao homem nesta vida. E com razão deseja uma longa vida aquele homem que a deseja para tornar-se mais perfeito neste bem. Ora, aquele que é mais perfejto na felicidade que, sabemos, pela razão, ser possivel ao homem nesta vida, é o que está mais próximo da felicidade que esperamos, pela fé, na vida futura. $E$ como um bem tão grande é possível ao homem, como já foi dito, é conveniente que todas as ações humanas dirijam-se a ele, a fim de obtê-lo.

As ações todas, com relação a uma lei, são retas e ordenadas quando tendem para fim da lei, e são tanto melhores quanto mais próximas ao fim da lei; mas as ações que se opṍem à lei, ou que são falhas (por não serem perfeitas segundo as determinações da lei), ou que são indiferentes (isto é, que nem se opõem ao fim da lei, nem são segundo os preceitos dela) - tais ações são defeito contra tal lei, po- 
dendo variar para mais e para menos na intensidade, como poderá ficar claro do que for dito. O mesmo acontece com os homens, pois todas as intenções e conselhos, ações e desejos dele, que tendem para o supremo bem que lhe é possivel, são retos e ordenados, como já foi dito. E quando o homem age assim, age naturalmente, pois age em vista do bem supremo para o qual está naturalmente voltado. E quando age assim, está devidamente ordenado, pois que está então ordenado para seu fim último e supremo. E todas as ações humanas que não se ordenam a este bem, ou que não são ações pelas quais o homem se torna mais forte e mais disposto às ações que ordenam a este bem - tais ações são defeito no homem. Por isso, o homem feliz só pratica as obras da felicidade, ou as obras pelas quais se torna mais forte e mais apto para as obras da felicidade. E assim o homem feliz quer durma, quer esteja desperto, quer coma - vive feliz, pois pratica tais ações a fim de tornar-se mais forte para as obras da felicidade.

Portanto, todas as ações do homem que não se dirigem a isto que é seu bem supremo, quer porque a ele se oponham, quer porque lhe sejam indiferentes - todas estas ações, como foi dito, são defeitos no homem, com maior ou menor intensidade, como é claro. E a causa de todas estas ações é a concupiscência desordenađa, que é também a causa de todos os maus costumes. De fato, a concupiscência desordenada do homem é a causa principal que o desvia de seu desejo natural. Todos os homens desejam naturalmente conhecer e, infelizmente, pouquíssimos entre eles entregam-se ao estudo da sabedoria, pois a concupiscência desordenada os impede de chegar a tão grande bem. Vemos que uns seguem a preguiça da vida, outros as detestáveis voluptuosidades sensíveis, outros o desejo de bens da fortuna. E assim, no dia de hoje, a concupiscência desordenada afasta do bem supremo a todos os homens, com exceção de uns pouquíssimos e venerandos. Chamo-os venerandos, porque desprezam o desejo do sentido e seguem o deleite e o desejo do intelecto, dedicando-se ao conhecimento da verdade das coisas; chamoos também de venerandos, porque vivem segundo a ordem natural. Todas as virtudes inferiores existentes no homem existem naturalmente em função da virtude suprema: assim, a força nutritiva existe para a sensitiva, pois a sensitiva é a perfeição de um certo corpo animado, e tal corpo pode existir sem alimento; ora, é a força nutritiva que modifica e transforma o alimento, e por isso a força nutritiva deve existir no homem em função da sensitiva. A força sensitiva, por sua vez, existe em função da intelectiva, pois em nós as coisas conhecidas provêm das imaginadas, e, por isso, entendemos de modo mais difícil aquilo que, em si, não pode ter em nós um conteúdo de imaginação. A imaginação, porém, só apreende algo após os sentidos o apreenderem - o que se prova pelo fato de que aquele que imagina algo, imagina-o como sensivel. Por isso, segundo diz o Filósofo (II De anima c. 3, 129a 12), a imaginação ou fantasia é um movimento provocado pelo sentido em ato. Assim, pois, as operações de todas as capacidades inferiores existentes no homem encontram-se em função das operações da virtude suprema, que é a inteligência. $\mathrm{E}$ entre as operações da capacidade intelectiva, se existe uma que é ótima e perfeitíssima, então as outras existem em vista dela. E o homem que se encontra em tal operação, encontra-se no melhor estado que lhe é possível. Ora, tais são os filósofos, que dedicam sua vida ao estudo da sabedoria. Por isso, todas as capacidades que existem no filósofo operam segundo a ordem natural: a anterior em função da 
posterior, e a inferior em vista da superior e da mais perfeita. Entrementes, ordenam-se de modo contrário à natureza e transgridem a ordem natural todos os demais homens que vivem segundo as virtudes inferiores, preferindo a prática delas e os deleites que nelas se encontram. Mas o fato de desviar-se da ordem natural constitui-se em defeito no homem; como, porém, o filósofo não se desvia desta ordem, também não peca contra ela.

Sob o aspecto moral, o filósofo é virtuoso por três motivos. Em primeiro lugar, porque conhece a turpidez da ação em que consiste o vício e a nobreza da ação em que consiste a virtude e, por isso, com mais facilidade pode escolher a uma e evitar a outra e agir sempre conforme a reta razão - pois quem assim age não peca. O mesmo não acontece com o ignorante, pois a este é difícil agir retamente. Em segundo lugar, porque aquele que experimentou o deleite maior despreza 0 menor; ora, o filósofo experimentou o deleite intelectual ao inquerir sobre a verdade dos seres, e tal deleite é maior que aquele dos sentidos; por isso, o filósofo despreza os deleites sensiveis. E muitos pecados e vícios encontram-se no abuso dos deleites sensiveis. Em terceiro lugar, porque no conhecer e no pesquisar não há pecado, pois não é possível o excesso e o pecado nos bens de todo simples. Mas a ação do filósofo é a procura da verdade. Logo, com maior facilidade que os outros o filósofo é virtuoso.

Por isso, o filósofo vive segundo o homem deve viver por natureza e de modo conforme à ordem natural, pois nele todas as forças inferiores e as ações delas constituem-se em função das forças superiores e de suas ações, e o conjunto todo, em função da virtude suprema e da ação última, que é a procura da verdade e o deleite nela, principalmente no que se refere à verdade primeira. De fato, o desejo de conhecer jamais se saciará, até que se conheça o ser incriado. A pergunta a respeito do intelecto divino, segundo Averróis (XI Metafísica c. 51), provém de um desejo natural de conhecer de todos os homens. Na verdade, o desejo que se volta para algo que pode ser conhecido é um certo desejo do primeiro cognoscível, o que se prova pelo fato de que quanto mais os entes se aproximam do primeiro cognoscível, tanto mais os desejamos conhecer e tanto mais nos deleitamos no estudo deles. Assim sendo, o filósofo, investigando os entes causados, que existem no mundo, bem como as naturezas e as relações entre eles, é levado à investigação das causas mais elevadas das coisas, pois o conhecimento dos efeitos é, de certo modo, uma introdução ao conhecimento de sua causa; e é levado ao conhecimento da causa primeira aquele que sabe que as causas superiores e suas naturezas são tais que é necessário que tenham uma outra causa. E na consideração consiste 0 deleite, e este é tanto maior quanto mais elevados forem os objetos considerados. Por isso, o filósofo leva uma vida cheia de voluptuosidade.

O mesmo lhe acontece ao conhecer e considerar que é necessário que esta causa seja a causa do ser para si mesma, isto é, que ela não tenha também uma causa. Se, porém, no mundo nada houvesse que não tivesse outra causa, então no conjunto não haveria nada.

Ele considera também a necessidade de que essa causa seja eterna e imutável, comportando-se sempre do mesmo modo, porque se ela não fosse eterna, então nada do conjunto do mundo seria eterno. Além disso, como algumas coisas no mundo são entes novos e um novo não pode ser a causa suficiente de outro novo - 
como é evidente por si - segue-se então manifestamente que todas as coisas novas existentes no mundo provêm no seu conjunto da causa eterna. Esta causa é também imutável, comportando-se sempre do mesmo modo, porque a mudança só é possivel nas coisas imperfeitas, e se existe algo neste mundo que é o ser perfeitíssimo, é digno então que seja a primeira causa.

Ele considera também que é necessário que todo o ser do mundo, que se encontra abaixo desta primeira causa, provenha dela, e que por isso a causa primeira é a causa da produção dos entes, tal como da ordenação deles entre si e de sua conservação no ser - de alguns deles conservando numericamente [os indivíduos], sem qualquer mutação, como no caso das substâncias separadas; de alguns, conservando numericamente, mas com mutação, como nos corpos celestes; e de alguns, apenas conservando a espécie, como no caso daquelas coisas que estão abaixo da esfera celeste, no grau ínfimo dos entes.

Ele considera também que, assim como todas as coisas provêm desta primeira causa, assim também estão ordenadas para ela. De fato, aquele ser, em quem o fundamento, do qual tudo procede, se une ao fim, ao qual tudo tende, tal ente é o ente primeiro, segundo os filósofos, e segundo os santos é o Deus bendito. Nesta ordem também existe um espaço e nele aqueles entes que estão mais próximos do primeiro princípio são mais nobres e mais perfeitos, enquanto os mais distantes do primeiro principio são entes diminutos e menos perfeitos. Este primeiro princípio encontra-se neste mundo como o pai de família na casa, o general no exército e o bem comum na cidade. E assim como o exército é uno devido à unidade de comando; e o bem por si do exército se encontra no general, enquanto nos outros encontra-se na medida em que se relacionam com o general - do mesmo modo, a unidade do mundo provém da unidade do primeiro princípio; e o bem por si deste mundo encontra-se neste primeiro princípio, enquanto nos demais entes do mundo o bem se encontra na medida da participação neste primeiro princípio e na ordenação para ele, de tal forma que não existe nenhum bem em qualquer ente do mundo, a não ser que participe deste primeiro princípio.

Considerando todas estas coisas, o filósofo é levado à admiração deste primeiro princípio e ao amor dele, pois nós amamos aquilo de onde nos provêm os bens supremos. Por isso o filósofo, sabendo que todos os seus bens provêm-lhe deste primeiro principio e por ele são-lhe conservados, é levado por este mesmo primeiro princípio a amá-lo com amor supremo, e isto acontece tanto segundo a reta razão da natureza, como segundo a reta razão da inteligência.

E como cada um deleita-se naquilo que ama, e tem o máximo deleite naquilo que ama ao máximo, e o filósofo ama ao máximo o primeiro princípio, tal como foi demonstrado - segue-se que o filósofo tem seu deleite supremo no primeiro principio e na contemplação de sua bondade. E só este é o deleite verdadeiro.

Esta é a vida do filósofo, e quem não a tiver, não possui uma vida correta. Chamo de filósofo a todo o homem que vive segundo a reta ordem da natureza e que alcançou o melhor e último fim da vida humana. O primeiro princípio, porém, a respeito do qual se tratou, é o Deus glorioso e sublime, que é bendito pelos séculos dos séculos. Amém. 